Ouachita Baptist University

Scholarly Commons@ Ouachita

Articles

Faculty Publications

9-14-2012

\title{
Resveratrol Effects on Astrocyte Function: Relevance to Neurodegenerative Diseases
}

\author{
Randall D. Wight \\ Cameron A. Tull \\ Ouachita Baptist University \\ Matthew W. Deel \\ Ouachita Baptist University \\ Brooke L. Stroope \\ Ouachita Baptist University \\ Amy G. Eubanks \\ Ouachita Baptist University \\ See next page for additional authors
}

Ouachita Baptist University, wight@obu.edu

Follow this and additional works at: https://scholarlycommons.obu.edu/articles

\section{Recommended Citation}

Wight, R. D., Tull, C. A., Deel, M. W., Stroope, B. L., Chavis, J. A., Drew, P. D., \& Hensley, L. L. (2012). Resveratrol effects on astrocyte function: Relevance to neurodegenerative diseases. Biochemical and Biophysical Research Communications, 426, 112-115. doi:10.1016/j.bbrc.2012.08.045 


\section{Authors}

Randall D. Wight, Cameron A. Tull, Matthew W. Deel, Brooke L. Stroope, Amy G. Eubanks, Janet A. Chavis, Paul D. Drew, and Lori L. Hensley 


\title{
Resveratrol effects on astrocyte function: relevance to neurodegenerative diseases
}

\author{
Randall D. Wight ${ }^{1}$, Cameron A. Tull ${ }^{1}$, Matthew W. Deel ${ }^{1}$, Brooke L. Stroope ${ }^{1}$, Amy G. \\ Eubanks ${ }^{1}$, Janet A. Chavis ${ }^{2}$, Paul D. Drew ${ }^{2}$, and Lori L Hensley ${ }^{1}$ \\ ${ }^{1}$ Department of Biology, Ouachita Baptist University, Arkadelphia, AR 71998 \\ ${ }^{2}$ Department of Neurobiology and Developmental Sciences, University of Arkansas for Medical \\ Sciences, Little Rock, AR 72205
}

\section{Abstract}

Inflammatory molecules have been implicated in the pathogenesis of neurodegenerative diseases such as Parkinson's disease, Alzheimer's disease, and multiple sclerosis. Resveratrol is an antifungal compound found in the skins of red grapes and other fruits and nuts. We examined the ability of resveratrol to inhibit lipopolysaccharide (LPS)-induced production of inflammatory molecules from primary mouse astrocytes. Resveratrol inhibited LPS-induced production of nitric oxide (NO); the cytokines tumor necrosis factor-alpha (TNF-a), interleukin 1-beta (IL-1 $\beta$ ), and IL-6; and the chemokine monocyte chemotactic protein-1 (MCP-1), which play critical roles in innate immunity, by astrocytes. Resveratrol also suppressed astrocyte production of IL-12p40 and IL-23, which are known to alter the phenotype of T cells involved in adaptive immunity. Finally resveratrol inhibited astrocyte production of C-reactive protein (CRP), which plays a role in a variety of chronic inflammatory disorders. Collectively, these studies suggest that resveratrol may be an effective therapeutic agent in neurodegenerative diseases initiated or maintained by inflammatory processes.

\section{Keywords}

Resveratrol; Astrocyte; Nitric oxide; Cytokine; Chemokine; C-reactive protein

\section{Introduction}

The role of inflammatory processes in the pathogenesis of neurodegenerative diseases is well accepted but poorly understood [1]. Poorly controlled or chronic inflammatory activation of microglia and astrocytes has been implicated in the development and worsening of Alzheimer's disease [2] Parkinson's disease [3] multiple sclerosis [4], and other neurodegenerative disorders [5].

Astrocytes, resident central nervous system (CNS) glial cells with multiple metabolic and neurotransmission functions, have been implicated in the initiation and maintenance of

\footnotetext{
(c) 2012 Elsevier Inc. All rights reserved.

Corresponding Author: Lori L. Hensley, Ph.D., Ouachita Baptist University Department of Biology, Jones Science Center Room 115, 410 Ouachita St. Box 3696, Arkadelphia, AR 71998, (870) 245-5529 Phone, (870) 245-5241 FAX, hensleyl@ obu.edu.

Publisher's Disclaimer: This is a PDF file of an unedited manuscript that has been accepted for publication. As a service to our customers we are providing this early version of the manuscript. The manuscript will undergo copyediting, typesetting, and review of the resulting proof before it is published in its final citable form. Please note that during the production process errors may be discovered which could affect the content, and all legal disclaimers that apply to the journal pertain.
} 
neurodegenerative processes and, alternatively, purported to protect against those processes$[3,6,7]$. Among the potential mechanisms for astrocytes contribution to disease development and progression, the effects of astrocyte responses to pathogens and pro-inflammatory cytokines appear likely. These responses include the production of nitric oxide (NO) and multiple cytokines and chemokines under the control of transcription factor nuclear factor $\kappa \beta$ (NF- $\kappa B$ ). While these molecules are essential to normal immune function, chronically high levels can interfere with normal function of the activated astrocyte and surrounding cells of the CNS [5].

Resveratrol, a naturally occurring phytogenic estrogen [8] found in the skin of grapes, red wine, mulberries, and several types of nuts, possesses anti-inflammatory properties [9]. Our study examines resveratrol's ability to suppress the production of inflammation-mediating molecules in primary astrocytes extracted from mice. Specifically, in LPS-induced astrocytes, we find dose-dependent effects of resveratrol on NO, TNF-a, IL-1 $\beta$, IL-6, MCP-1, IL-12p40, IL-23, and CRP. Given the role that chronically elevated levels of these molecules may play in neurodegeneration, these findings suggest resveratrol may be an effective agent for preventing or treating neurodegenerative diseases initiated or maintained by inflammatory processes.

\section{Materials and methods}

Primary astrocyte cultures were obtained through a modification of the McCarthy and deVellis protocol [10]. Briefly, cerebral cortices from 1-2 day-old C57BL/6 mice were excised, meninges removed, and cortices minced into small pieces. Cells were separated by trypsinization followed by trituration of cortical tissue. Cells were plated into tissue culture flasks and allowed to grow to confluence (approximately 10 days) in DMEM media containing 10\% FBS, 1.4mM glutamine, and OPI media supplement (Sigma, St. Louis, MO). Flasks were shaken overnight $\left(200 \mathrm{rpm}\right.$ at $\left.37^{\circ} \mathrm{C}\right)$ in a temperature controlled shaker to loosen microglia and oligodendrocytes from the more adherent astrocytes. L-LME $(0.1 \mathrm{mM})$ was added to the cultures to eliminate any residual microglia. Using this procedure, astrocyte cultures of greater than $95 \%$ purity were obtained as determined by immunohistochemistry with antibodies prepared against GFAP for astrocytes and the lectin, Griffonia simplicifolia (GSA) to measure contaminating microglia. Astrocytes were seeded into 96-well plates. The following day, cultures were treated for $1 \mathrm{~h}$ with the indicated concentrations of resveratrol followed by treatment for $24 \mathrm{~h}$ with $2 \mu \mathrm{g} / \mathrm{ml}$ lipopolysaccharide (LPS). Tissue culture supernatants and cells were collected for cell viability, nitrite, and ELISA assays, which were conducted as we have described previously [11].

\section{Results}

Resveratrol inhibited NO production in a dose-dependent manner (Figure 1A). Resveratrol was not toxic to astrocytes in these studies as determined by MTT assays, indicating that resveratrol suppression of $\mathrm{NO}$ by primary astrocytes was not due to astrocyte cell death (Figure 1B).

LPS induced the production of inflammatory cytokines TNF-a (Figure 2A), IL-1 $\beta$ (Figure 2B), IL-6 (Figure 2C), and MCP-1 (Figure 2D) which are molecules that play critical roles in innate immunity. In addition, resveratrol inhibited LPS induction of IL-12 (Figure 3A) and IL-23 (Figure 3B), which are cytokines that are capable of altering the phenotype of T cells that are critical to adaptive immunity. Finally, resveratrol suppressed LPS-induction of CRP (Figure 4) by primary astrocytes, and CRP has been associated with a variety of chronic inflammatory disorders. Resveratrol suppressed astrocyte production of these inflammatory molecules in a dose-dependent manner. Collectively, these studies indicate that resveratrol is effective in the suppression of a variety of pro-inflammatory molecules, 
and thus may be effective in the treatment of neuroinflammatory and neurodegenerative disorders.

\section{Discussion}

Resveratrol has been shown to be neuroprotective against ischemia-induced injury [12], $\beta$ amyloid-induced neurotoxicity [13], autoimmune-mediated injury [14], and various other inflammation-mediated contributors to neuronal cell death and dysfunction [15]. Recent studies have examined the effects of resveratrol on specific pro-inflammatory molecules in the CNS, including NO [16] and cytokines under the influence of NF- $k \beta$ [17]. However, most studies of relevance to neurodegenerative diseases have focused on resveratrol's effects in microglia and not astrocytes.

As reviewed by Quincozes-Santos \& Gottfried [18], many of the neuroprotective effects of resveratrol may be mediated by the compound's modulatory actions on astrocytes. Potentially protective actions in astrocytes include modulation of glutamate homeostasis, modulation of ischemia-induced mitochondrial dysfunction, and suppression of acute and chronic inflammation.

A recent study indicated that resveratrol's effects on mediators of inflammation may not be identical in microglia and astrocytes. Lu and colleagues [19] found that resveratrol was a more potent suppressor of TNF-a, IL-6, MCP-1, and NO production in mouse microglia than in mouse astrocytes. They also found that resveratrol suppressed IL-1 $\beta$ production in microglia but not in astrocytes. In contrast, we found that resveratrol significantly suppressed IL- $1 \beta$ production at concentrations that did not affect the viability of astrocytes. Interestingly, we also demonstrate for the first time that resveratrol inhibits LPS induction of IL-12p40 and IL-23 by primary astrocytes. These cytokines play a critical role in the differentiation of Th1 and Th17 cells known to contribute to the development of experimental autoimmune encephalomyelitis (EAE), an animal model of multiple sclerosis [20]. Resveratrol suppresses the development of EAE [14] Our studies suggest that resveratrol may suppress EAE, at least in part, through suppressing the development of Th1 and Th17 cells.

The potential link between elevated serum levels of CRP and cardiopathology has received significant attention. More recent studies suggest a potential link between high serum levels of CRP with the presence and severity of AD [21] and PD [22,23,24], suggesting a role of CRP in the pathogenesis of neurodegenerative diseases. A recent study indicates that proinflammatory cytokines induce CRP expression in primary microglia [25]. To the best of our knowledge, the current study is the first demonstration of CRP expression by astrocytes and the first to demonstrate that resveratrol inhibits LPS-induction of CRP production in these cells. These studies suggest that resveratrol may suppress the development of neurodegenerative diseases in part by suppressing CRP expression by astrocytes.

In summary, we demonstrated that resveratrol inhibits astrocyte production of several molecules implicated in innate immunity and neurodegeneration. Furthermore, we demonstrate for the first time that resveratrol suppresses the production of IL-12 and IL-23. This suggests that resveratrol could suppress EAE by suppressing the development of Th1 and Th2 cells. Finally, we present the first evidence that resveratrol suppresses astrocyte production of CRP. Collectively, these studies suggest that resveratrol may prove valuable in the treatment of CNS diseases characterized by neuroinflammation and neurodegeneration. 


\section{Acknowledgments}

The authors thank Barry Gehm and Timothy Hayes for helpful discussions, and Sean Daly for technical assistance. This work was supported by NIH grants NCRR 5P20RR016460-11, NIGMS 8P20GM103429-11 and NS047546.

\section{References}

1. Minghetti L. Role of inflammation in neurodegenerative diseases. Curr Opin Neurol. 2005; 18:315321. [PubMed: 15891419]

2. Zhao J, O'Connor T, Vassar R. The contribution of activated astrocytes to Abeta production: implications for Alzheimer's disease pathogenesis. J Neuroinflammation. 2011; 8:150. [PubMed: 22047170]

3. Teismann P, Schulz JB. Cellular pathology of Parkinson's disease: astrocytes, microglia and inflammation. Cell Tissue Res. 2004; 318:149-161. [PubMed: 15338271]

4. Trapp BD, Nave KA. Multiple sclerosis: an immune or neurodegenerative disorder? Annu Rev Neurosci. 2008; 31:247-269. [PubMed: 18558855]

5. Glass CK, Saijo K, Winner B, Marchetto MC, Gage FH. Mechanisms underlying inflammation in neurodegeneration. Cell. 2010; 140:918-934. [PubMed: 20303880]

6. Nair A, Frederick TJ, Miller SD. Astrocytes in multiple sclerosis: A product of their environment. Cell Mol Life Sci. 2008; 65:2702-2720. [PubMed: 18516496]

7. Williams A, Piaton G, Lubetzki C. Astrocytes--friends or foes in multiple sclerosis? Glia. 2007; 55:1300-1312. [PubMed: 17626262]

8. Gehm BD, McAndrews JM, Chien PY, Jameson JL. Resveratrol, a polyphenolic compound found in grapes and wine, is an agonist for the estrogen receptor. Proc Natl Acad Sci U S A. 1997; 94:14138-14143. [PubMed: 9391166]

9. Das S, Das DK. Anti-inflammatory responses of resveratrol. Inflamm Allergy Drug Targets. 2007; 6:168-173. [PubMed: 17897053]

10. McCarthy KD, de Vellis J. Preparation of separate astroglial and oligodendroglial cell cultures from rat cerebral tissue. J Cell Biol. 1980; 85:890-902. [PubMed: 6248568]

11. Xu J, Drew PD. Peroxisome proliferator-activated receptor-gamma agonists suppress the production of IL-12 family cytokines by activated glia. J Immunol. 2007; 178:1904-1913. [PubMed: 17237441]

12. Tsai SK, Hung LM, Fu YT, Cheng H, Nien MW, Liu HY, Zhang FB, Huang SS. Resveratrol neuroprotective effects during focal cerebral ischemia injury via nitric oxide mechanism in rats. $\mathbf{J}$ Vasc Surg. 2007; 46:346-353. [PubMed: 17600658]

13. Han YS, Zheng WH, Bastianetto S, Chabot JG, Quirion R. Neuroprotective effects of resveratrol against beta-amyloid-induced neurotoxicity in rat hippocampal neurons: involvement of protein kinase C. Br J Pharmacol. 2004; 141:997-1005. [PubMed: 15028639]

14. Shindler KS, Ventura E, Dutt M, Elliott P, Fitzgerald DC, Rostami A. Oral resveratrol reduces neuronal damage in a model of multiple sclerosis. J Neuroophthalmol. 2010; 30:328-339. [PubMed: 21107122]

15. Sun AY, Wang Q, Simonyi A, Sun GY. Resveratrol as a therapeutic agent for neurodegenerative diseases. Mol Neurobiol. 2010; 41:375-383. [PubMed: 20306310]

16. Bi XL, Yang JY, Dong YX, Wang JM, Cui YH, Ikeshima T, Zhao YQ, Wu CF. Resveratrol inhibits nitric oxide and TNF-alpha production by lipopolysaccharide-activated microglia. Int Immunopharmacol. 2005; 5:185-193. [PubMed: 15589480]

17. Surh YJ, Chun KS, Cha HH, Han SS, Keum YS, Park KK, Lee SS. Molecular mechanisms underlying chemopreventive activities of anti-inflammatory phytochemicals: down-regulation of COX-2 and iNOS through suppression of NF-kappa B activation. Mutat Res. 2001; 480-481:243268.

18. Quincozes-Santos A, Gottfried C. Resveratrol modulates astroglial functions: neuroprotective hypothesis. Ann N Y Acad Sci. 2011; 1215:72-78. [PubMed: 21261643] 
19. Lu X, Ma L, Ruan L, Kong Y, Mou H, Zhang Z, Wang Z, Wang JM, Le Y. Resveratrol differentially modulates inflammatory responses of microglia and astrocytes. $\mathrm{J}$ Neuroinflammation. 2010; 7:46. [PubMed: 20712904]

20. Petermann F, Korn T. Cytokines and effector T cell subsets causing autoimmune CNS disease. FEBS Lett. 2011; 585:3747-3757. [PubMed: 21477588]

21. Holmes C, Cunningham C, Zotova E, Woolford J, Dean C, Kerr S, Culliford D, Perry VH. Systemic inflammation and disease progression in Alzheimer disease. Neurology. 2009; 73:768774. [PubMed: 19738171]

22. Song IU, Chung SW, Kim JS, Lee KS. Association between high-sensitivity C-reactive protein and risk of early idiopathic Parkinson's disease. Neurol Sci. 2011; 32:31-34. [PubMed: 20532580]

23. Hassin-Baer S, Cohen OS, Vakil E, Molshazki N, Sela BA, Nitsan Z, Chapman J, Tanne D. Is Creactive protein level a marker of advanced motor and neuropsychiatric complications in Parkinson's disease? J Neural Transm. 2011; 118:539-543. [PubMed: 21161711]

24. Zhang L, Yan J, Xu Y, Long L, Zhu C, Chen X, Jiang Y, Yang L, Bian L, Wang Q. The combination of homocysteine and C-reactive protein predicts the outcomes of Chinese patients with Parkinson's disease and vascular parkinsonism. PLoS One. 2011; 6:e19333. [PubMed: 21556377]

25. Juma WM, Lira A, Marzuk A, Marzuk Z, Hakim AM, Thompson CS. C-reactive protein expression in a rodent model of chronic cerebral hypoperfusion. Brain Res. 2011; 1414:85-93. [PubMed: 21840509] 
- Resveratrol inhibited astrocyte production of cytokines and chemokines.

- Resveratrol inhibited production of C-reactive protein by astrocytes.

- Resveratrol may be effective in the treatment of neurodegenerative diseases. 
A

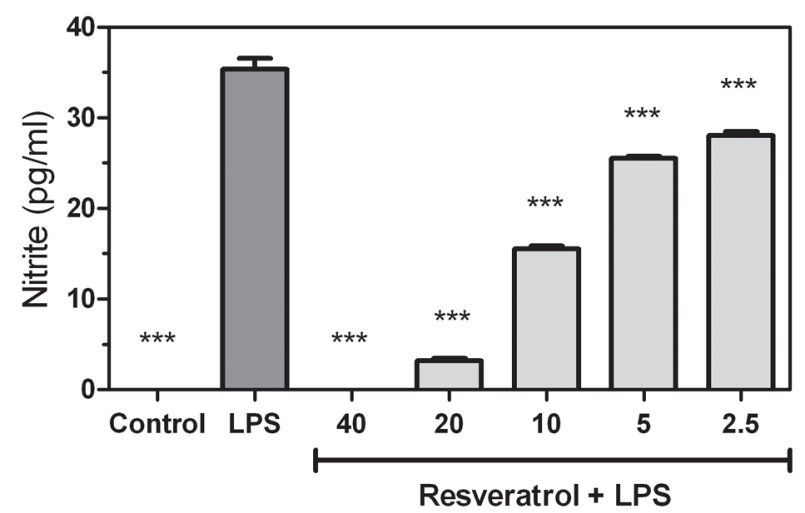

B

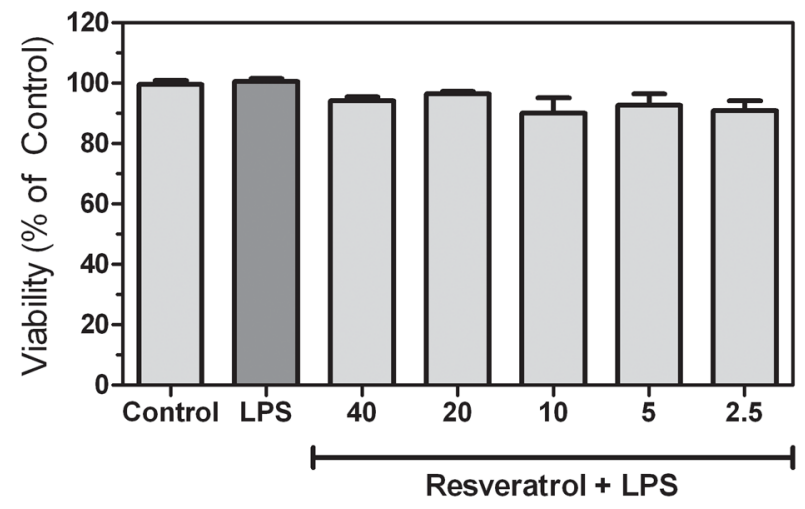

Figure 1. Resveratrol suppresses production of nitrite in LPS-stimulated primary astrocytes Cells were pre-treated for $1 \mathrm{~h}$ with the indicated concentrations of resveratrol $(\mu \mathrm{g} / \mathrm{ml})$. LPS $(2 \mu \mathrm{g} / \mathrm{ml})$ was added and cells were incubated for $24 \mathrm{~h}$. The concentration of nitrite was measured using Greiss reaction (A). Cell viability was determined by MTT assay (B), and resveratrol had no effect on cell viability. Values represent the mean $+/-$ s.e.m. for triplicate cultures. $* * *$ indicates $\mathrm{p}<.001$ vs. LPS treated cultures. Data were analyzed by ANOVA followed by a Bonferroni test to determine the significance of difference. These data are representative of three independent experiments. 
A
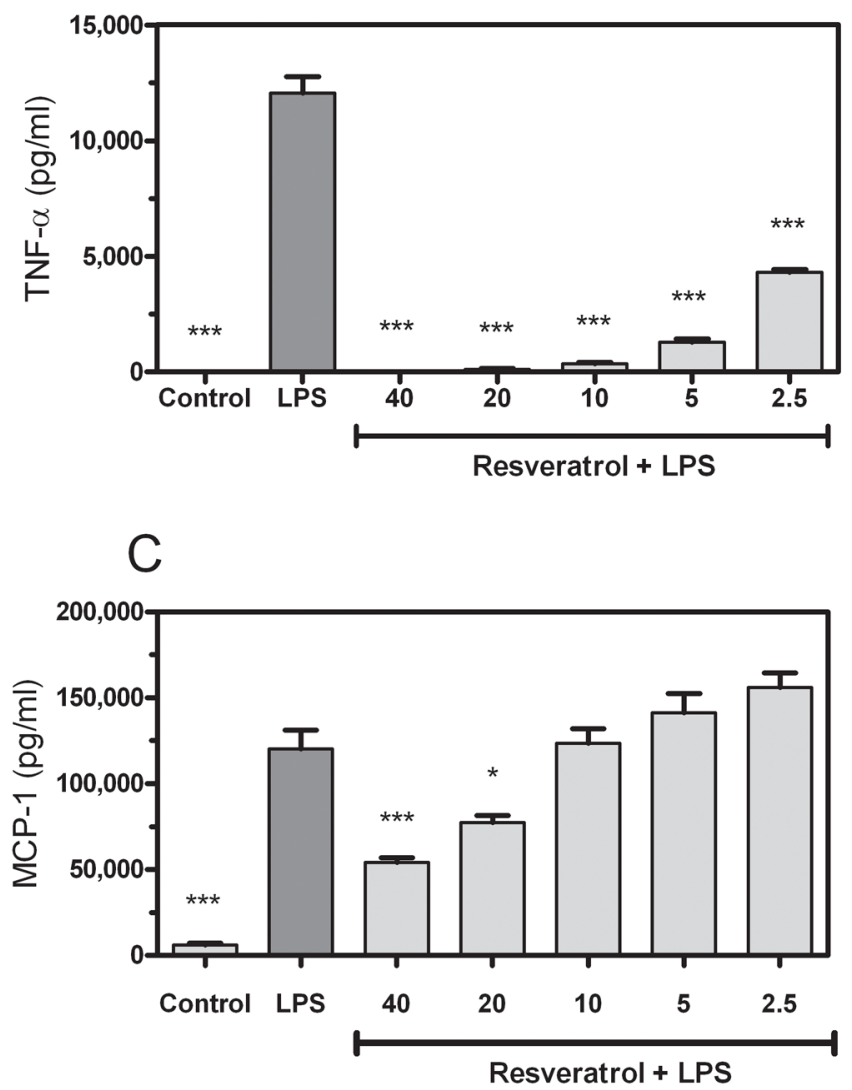

B

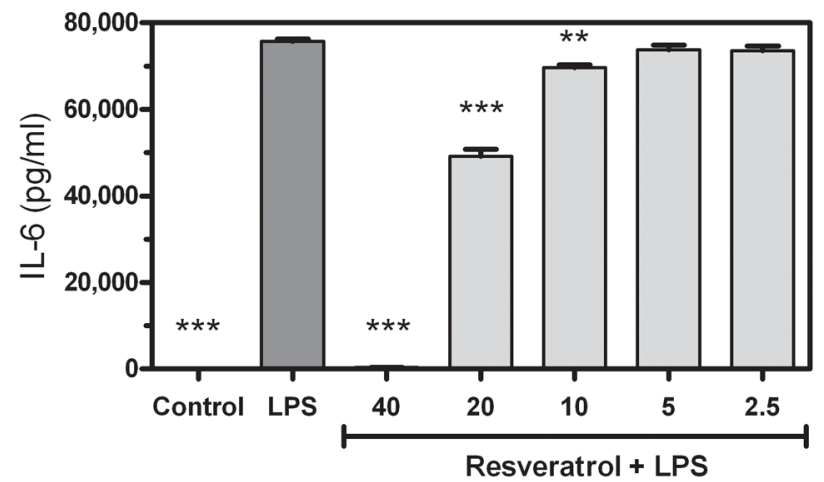

D

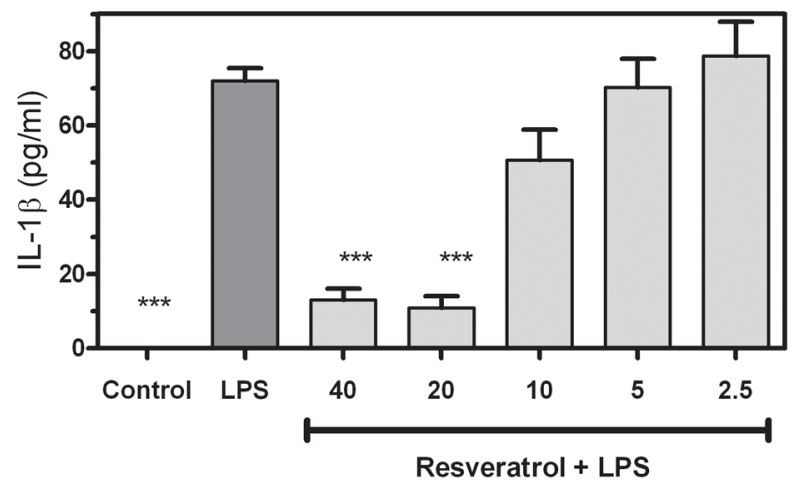

Figure 2. Resveratrol suppresses production of inflammatory mediators by primary astrocytes Cells were pre-treated with resveratrol at the indicated concentration $(\mu \mathrm{g} / \mathrm{ml})$ for $1 \mathrm{~h}$, LPS $(2 \mu \mathrm{g} / \mathrm{ml})$ was added, and cells were incubated for $24 \mathrm{~h}$. Concentrations of inflammatory mediators (TNF-a, A; IL-1 $\beta$, B; IL-6, C; and MCP-1, D) in the culture medium were determined by ELISA. Values represent the mean $+/-$ s.e.m. for triplicate cultures. * indicates $\mathrm{p}<.05, * *$ indicates $<.01$, and $* * *$ indicates $<.001$ vs. LPS treated cultures. Data were analyzed by ANOVA followed by a Bonferroni test to determine the significance of difference. These data are representative of three independent experiments. 
A

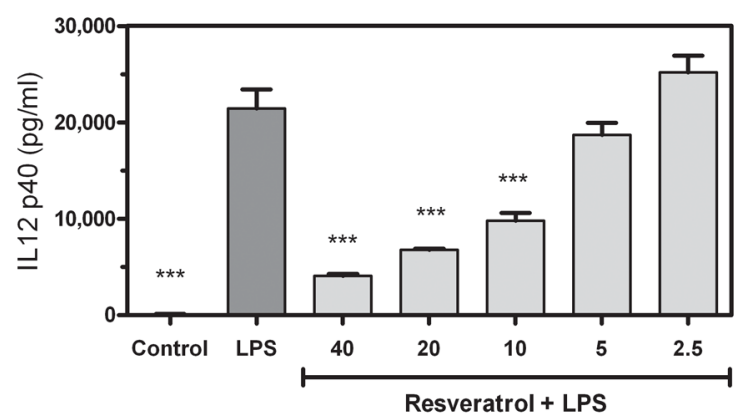

$\mathrm{B}$

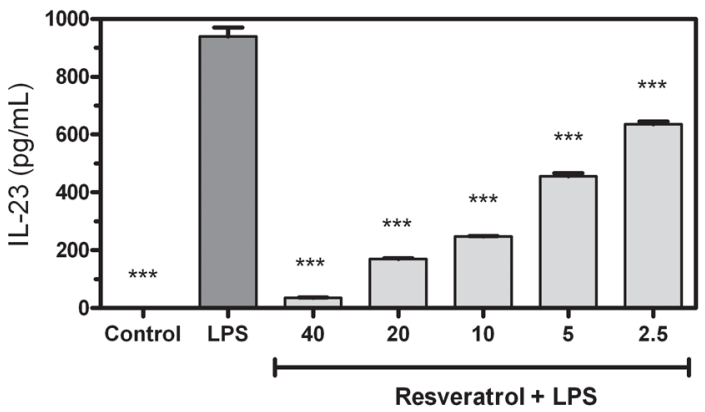

Figure 3. Resveratrol suppresses production of IL-12 family cytokines by primary astrocytes Cells were pre-treated with resveratrol at the indicated concentration $(\mu \mathrm{g} / \mathrm{ml})$ for $1 \mathrm{~h}$, LPS $(2 \mu \mathrm{g} / \mathrm{ml})$ was added, and cells were incubated for $24 \mathrm{~h}$. Concentrations of inflammatory mediators (IL-12p40, A; and IL-23, B) in the culture medium were determined by ELISA. Values represent the mean $+/-$ s.e.m. for triplicate cultures. ***indicates $\mathrm{p}<.001 \mathrm{vs.} \mathrm{LPS}$ treated cultures. Data were analyzed by ANOVA followed by a Bonferroni test to determine the significance of difference. These data are representative of three independent experiments. 


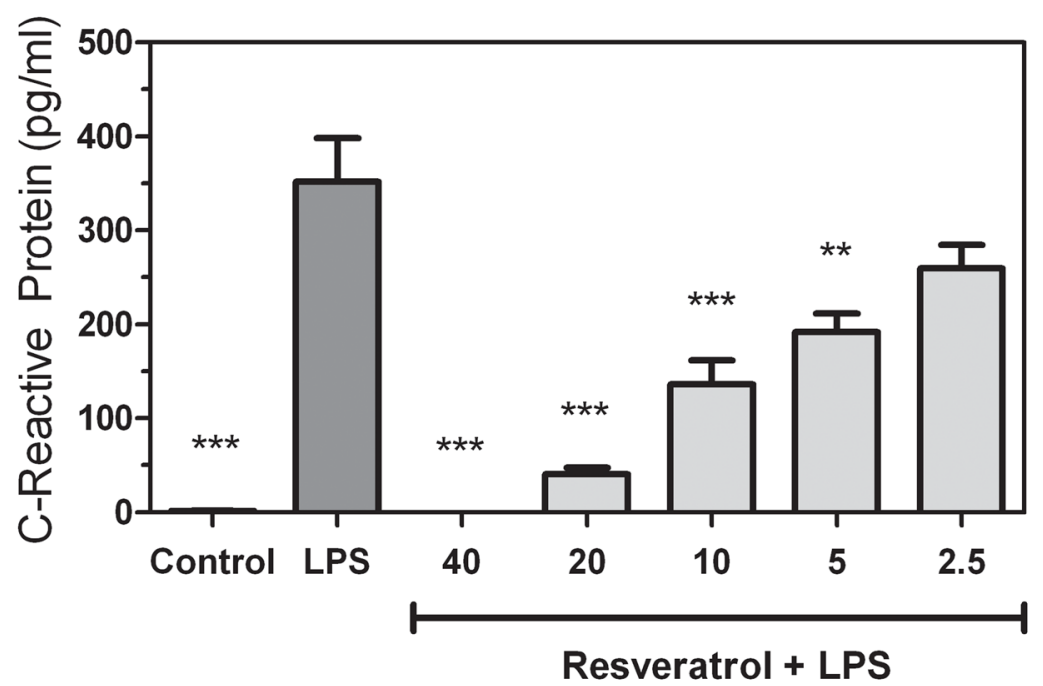

Figure 4. Resveratrol suppresses production of C-reactive protein by primary astrocytes Cells were pre-treated with resveratrol at the indicated concentration $(\mu \mathrm{g} / \mathrm{ml})$ for $1 \mathrm{~h}, \mathrm{LPS}$ $(2 \mu \mathrm{g} / \mathrm{ml})$ was added, and cells were incubated for $24 \mathrm{~h}$. Concentrations of CRP in the culture medium were determined by ELISA. Values represent the mean $+/-$ s.e.m. for triplicate cultures. $* *$ indicates $\mathrm{p}<.01$, and $* * *$ indicates $<.001$ vs. LPS treated cultures. Data were analyzed by ANOVA followed by a Bonferroni test to determine the significance of difference. These data are representative of three independent experiments. 